\title{
COMPARATIVE ANALYSIS OF THE EVACUATION BY AN ESTIMATED TSUNAMI AND THE 2011 OFF THE PACIFIC COAST OF TOHOKU EARTHQUAKE IN CASE OF ONJUKU, CHIBA
}

\author{
Takuro KAWASAKI ${ }^{1}$, Osamu MURAO ${ }^{2}$, Teruyuki ISAGAWA ${ }^{3}$ and Ryuzo OHNO ${ }^{4}$ \\ ${ }^{1}$ Former Graduate Student, Graduate School of Systems and Information Science, \\ University of Tsukuba, Tsukuba, Japan \\ ${ }^{2}$ Member of JAEE, Professor, International Research Institute of Disaster Science, Tohoku University \\ Sendai, Japan,murao@irides.tohoku.ac.jp \\ ${ }^{3}$ Post Doctoral Researcher, Interdisciplinary Graduate School of Science and Engineering, \\ Tokyo Institute of Technology, Tokyo, Japan \\ ${ }^{4}$ Professor, Interdisciplinary Graduate School of Science and Engineering, \\ Tokyo Institute of Technology, Tokyo, Japan
}

\begin{abstract}
After the Great East Japan Earthquake, importance of tsunami evacuation is increasingly acknowledged. The authors conducted questionnaire surveys of residents' evacuation in Onjuku, Chiba, focusing on an estimated tsunami in 2008 and on the event. Then acquired evacuation spatial data are compared in terms of altitude, distance from the coastal line, and the number of people in the inundated area. As a result, the actual evacuation activities in comparison with the estimated showed (1) diversity, (2) numerous uses of cars, (3) longer distance, and (4) more people in the inundation area.
\end{abstract}

Key Words: 2011 Great East Japan Earthquake and Tsunami, Onjuku, tsunami, evacuation action, GIS

\section{INTRODUCTION}

\subsection{Research background}

The tsunami generated by the Great East Japan Earthquake on March 11, 2011 (MW = 9.0) caused enormous damage along the length of eastern Japan and resulted in more than 15,000 deaths and 3,000 missing. As a result, a turning point has been reached concerning tsunami disaster reduction. In particular, the limitations of "hard" countermeasures and earthquake prediction are being discussed by the Central Disaster Management Council and relevant academic societies ${ }^{1), 2)}$, and the importance of tsunami evacuation as preparation against the largest class of earthquakes/tsunami is being given more recognition than ever before. With regard to future tsunami disaster reduction, the Central Disaster Management Council will, "with highest priority given to protecting the lives of the population, establish comprehensive tsunami countermeasures embracing every possible means and placing evacuation at the core", and there is an urgent need to plan effective tsunami disaster reduction 
measures that take the Great East Japan Earthquake disaster into consideration throughout Japan ${ }^{2)}$.

The mainstream of research on tsunami evacuation behavior in recent years has used multi-agent simulation methods, such as Fujioka et al. ${ }^{3)}$, Katada et al. ${ }^{4)}$, and Watanabe/Kondo ${ }^{5)}$. Multi-agent simulations comprise agents and environments. For many cases, it is possible to reproduce complex phenomena by taking evacuees as agents and providing environments that influence their behavior. This study differs from previous research in that it uses questionnaire surveys to understand the behavior of evacuees. This makes it possible to reproduce the evacuation behavior that takes place when a disaster has actually occurred in a form that is as close to reality as possible, without relying on predictive values obtained from, for example, multi-agent simulations. The information obtained from questionnaire surveys also makes it possible to understand patterns of behavior that were difficult to see in the previous research on tsunami evacuation.

The authors of this paper conducted a "Tsunami Evacuation Questionnaire Survey" in 2008 (before the Great East Japan Earthquake disaster) in Onjuku, a town located on the east coast of Chiba Prefecture. The survey asked about "general awareness of tsunami protection under normal circumstances" and "intentions regarding evacuation behavior during a tsunami", and had participants describe their envisioned evacuation route on a map. The summarized results were statistically processed and have already been published by Isagawa and Murao ${ }^{6}$. However, the analysis of representing the obtained evacuation information spatially remained to be done. The Great East Japan Earthquake disaster struck on March 11, 2011 while this analysis was being conducted, and evacuation behavior was performed in response to a real tsunami in various places in eastern Japan. In light of this, the authors of this paper conducted an additional survey in Onjuku entitled "Questionnaire Survey on Behavior Directly after the Great East Japan Earthquake". This survey made it possible to compare the evacuation behavior that people living along the coast in Onjuku envisioned in the case of an earthquake disaster and their actual evacuation behavior.

\subsection{Research aims and methods}

On the basis of the above background, this research focused on the evacuation behavior of coastal inhabitants of Onjuku and aimed to determine "tsunami evacuation behavior envisioned under normal circumstances" and "behavior actually exhibited during a real tsunami" on the basis of questionnaire surveys conducted in 2008 and 2011, respectively. It also aimed to evaluate the planning/behavior of inhabitants in respect to tsunami and offer suggestions regarding "soft" disaster prevention for the largest class of tsunami.

First, spatial information on evacuation routes obtained from the 2008 questionnaire survey was aggregated using GIS and understood as spatiotemporal information. Then, the spatial information for these evacuation routes was examined from the point of view of (1) height above sea level, (2) distance from the coastline, and (3) number of people remaining in estimated flood zones.

Next, the emergency response in Onjuku on March 11, 2011 was ascertained through interviews with the authorities. Then, in the same way as the 2008 questionnaire survey, the summarized results of the survey conducted in August 2011 were considered from the point of view of (1) height above sea level, (2) distance from the coastline, and (3) number of people remaining in estimated flood zones.

Finally, the results of the two questionnaire surveys on evacuation behavior were compared, and differences between the envisioned evacuation behavior and the actual evacuation behavior were examined.

\section{SPATIAL ANALYSIS OF ENVISIONED TSUNAMI EVACUATION BEHAVIOR BASED ON 2008 QUESTIONNAIRE SURVEY}

\subsection{Overview of 2008 questionnaire survey}

This section gives an overview of the "Tsunami Evacuation Questionnaire Survey"6) conducted in 2008 to understand intentions regarding envisioned evacuation behavior. The survey was conducted 
with the aim of identifying "inhabitants' awareness of tsunami protection" and "intentions regarding evacuation behavior during a tsunami" taking into account the regional characteristics of Onjuku. The survey questions were broadly divided into the following three categories:

\subsubsection{Questions on tsunami protection awareness}

Recognition of tsunami risk/interest in disaster prevention (recognition of flood risk of own home, knowledge of past tsunami, interest in disaster reduction activities in general, degree of contact with hazard maps, and whether and how hazard maps proved useful in improving awareness) and execution of disaster prevention measure activities (participation in workshops, participation in voluntary disaster prevention meetings, participation in municipal disaster drills, and preparations in home).

\subsubsection{Questions on intentions regarding behavior during a tsunami}

Whether they intend to evacuate/timing of decision-making, evacuation site, evacuation route, evacuation means, and accompanying people.

Answers were given in response to the following scenario based on the circumstances of the 1703 Genroku Earthquake and tsunami (which formed the basis for the Onjuku hazard maps) and the Japan Meteorological Agency's system for announcing earthquake, tsunami, etc., information.

You are in your own home. An earthquake occurs south of the Boso Peninsula at 12 noon, and you feel the tremors. About 3 minutes later, the following tsunami warning is issued:

- The expected time of arrival of the tsunami in the town is around 12:15.

- The expected height of the tsunami in the town is 8 meters.

\subsubsection{Individual attribute/Other}

District, sex, age, number of people in household, number of years of residence, and whether there are people in the household who may have difficulty evacuating.

The survey was conducted in December 2008 and covered all households in six districts within Onjuku. The survey forms were distributed together with a public relations magazine, and 564 forms were returned out of 2,285 distributed (recovery rate $24.7 \%$ ).

\subsection{Awareness/intentions regarding tsunami before earthquake disaster}

Based on the results of the 2008 survey, Isagawa and $\mathrm{Murao}^{6}$ ) examined awareness/intentions regarding tsunami, focusing on space and individuals, and derived the four conclusions given below.

(1) Recognition of tsunami risk varied in a stepwise manner according to the expected extent of flooding. However, there was little relation between the timing of decision-making regarding evacuation during a tsunami and the expected extent of flooding. (2) Distance of place of residence from the coast and height above sea level were shown to have a large influence on recognition of tsunami risk. However, no relation between these factors and timing of decision-making was found. (3) The individual attributes dealt with in this survey were not found to have any direct effect on tsunami awareness or evacuation intentions. (4) Some inhabitants were thinking of taking actions that could increase danger during evacuation.

\subsection{Spatial analysis of evacuation behavior of inhabitants}

This section examines the analysis of evacuation routes that was not included in the report by Isagawa and Murao ${ }^{6)}$ mentioned in Section 1.

\subsubsection{Basic information}

The target area was affected by the tsunami that accompanied the Empo Boso-oki Earthquake (1677) and the Genroku Earthquake (1703). According to Takeuchi et al. ${ }^{7)}$, records on the Empo Boso-oki Earthquake disaster show 170 houses washed away and 53 deaths due to a tsunami, with an estimated 
inundation depth of $2.0 \mathrm{~m}$ or more. In the case of damage in Onjuku caused by the Genroku Earthquake and tsunami, Tsuji ${ }^{8)}$ calculated 20 deaths and 258 houses washed away. Flood risk zones estimated on the basis of these earthquakes/tsunami are used in the hazard maps for Chiba Prefecture (Fig. 1). The base map used for aggregation/analysis of the obtained data was prepared using the basic cartographic information ${ }^{9)}$ published on the Internet by the Geospatial Information Authority of Japan (Fig. 2).

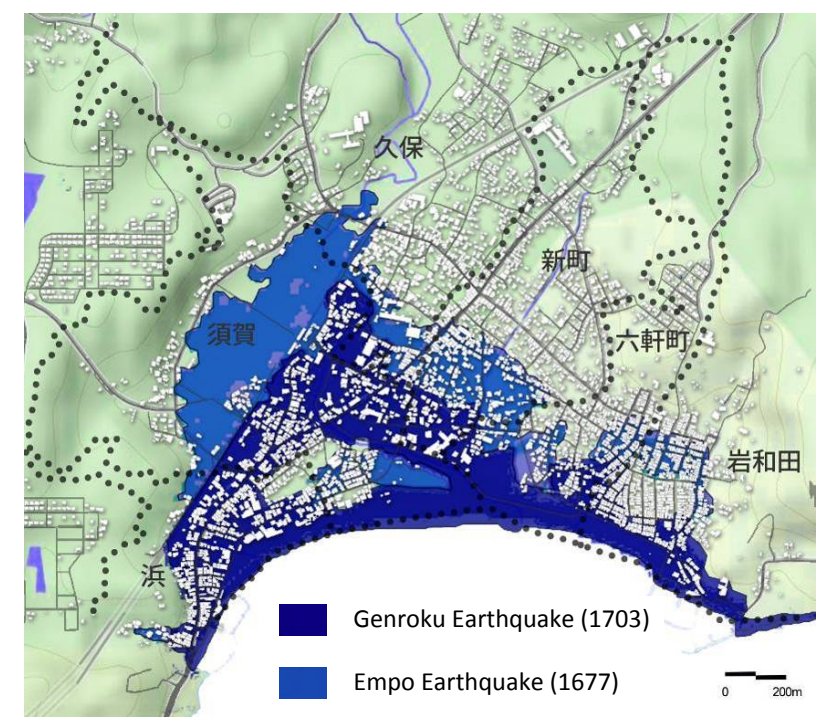

Fig. 1 Target area and tsunami flood risk zones assuming Empo/Genroku earthquakes (Prepared based on Google Maps and Chiba Prefecture hazard maps)

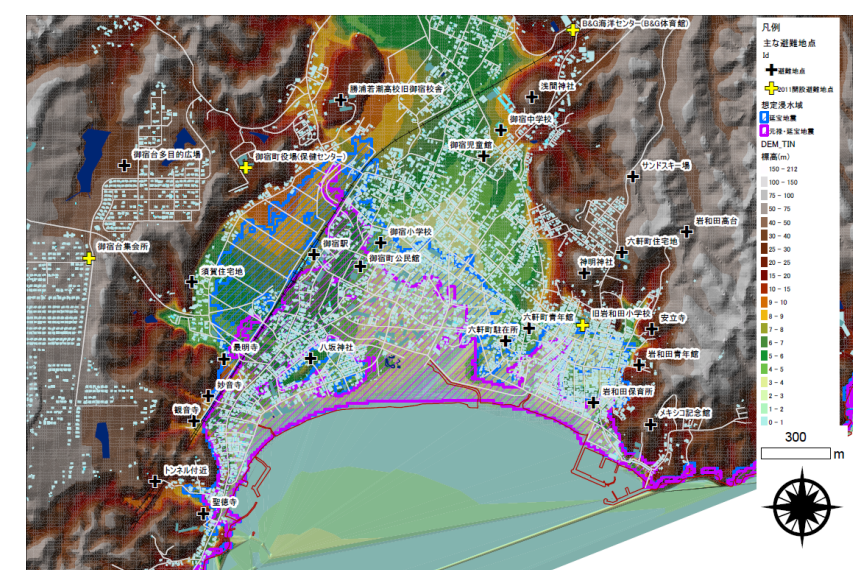

Fig. 2 Base map

The data on participants' envisioned evacuation routes obtained via the questionnaire survey were inputted into the base map, and an analysis that incorporated the concept of time was carried out. "Whether they intend to evacuate/timing of decision-making" and "evacuation means" were inputted as attributes of the inputted evacuation routes. These were given as evacuation start time and speed of each respondent based on the operations in Table 1. Evacuation start time was established on the basis of the envisioned scenario set in the questionnaire survey. In the scenario, the tsunami warning is issued after 3 minutes and the tsunami strikes after 15 minutes. Also, "after I am called to evacuate" and "after my neighbors start to evacuate" are tentatively set at after 5 minutes and 7 minutes, respectively. Evacuation speed was set based on previous research by Ishida et al. ${ }^{10)}$ and converted to 
distance per minute. External factors such as traffic congestion are difficult to estimate and so were not considered in this survey.

Table 1 Answers used in analysis of evacuation behavior and evacuation speed settings for different means of evacuation

\begin{tabular}{|c|c|c|}
\hline Timing of evacuation decision-making $(\mathrm{n}=457)$ & No. of replies & Evacuation start time (minutes) \\
\hline As soon as I feel a tremor & 25 & $\mathrm{t}=0$ \\
\hline As soon as a tsunami warning is issued & 239 & $\mathrm{t}=3$ \\
\hline After I am called to evacuate & 168 & $\mathrm{t}=5$ \\
\hline After my neighbors start to evacuate & 24 & $\mathrm{t}=7$ \\
\hline When I can see the tsunami & 1 & $\mathrm{t}=15$ \\
\hline Evacuation means $(\mathrm{n}=455)$ & No. of replies & Evacuation speed (meters/minute) \\
\hline Walking & 365 & 67 \\
\hline Bicycle & 20 & 167 \\
\hline Motorcycle & 4 & 333 \\
\hline Car & 66 & 500 \\
\hline
\end{tabular}

Evacuee location at time $t$ can be established using the above operations. Fig. 3 shows distributions of evacuees calculated using the above-mentioned method (after $\mathrm{t}=5,10,15$, and 20 minutes; only questionnaire respondents shown). Gray dots represent locations of inhabitants who are evacuating at the time point and are based on the actual road network. The black circles indicate evacuation points (evacuation point names correspond to those in Fig. 2), and the size of each circle corresponds to the final number of evacuees. Evacuees who have not started evacuating or who have finished evacuating are not shown. In this way, the distribution of evacuees $t$ minutes after the earthquake occurs can be predicted. Next, in order to evaluate the evacuation behavior, analyses providing three indices to evacuee positional information - height above sea level, distance from coastline, and estimated flood zones-were conducted.

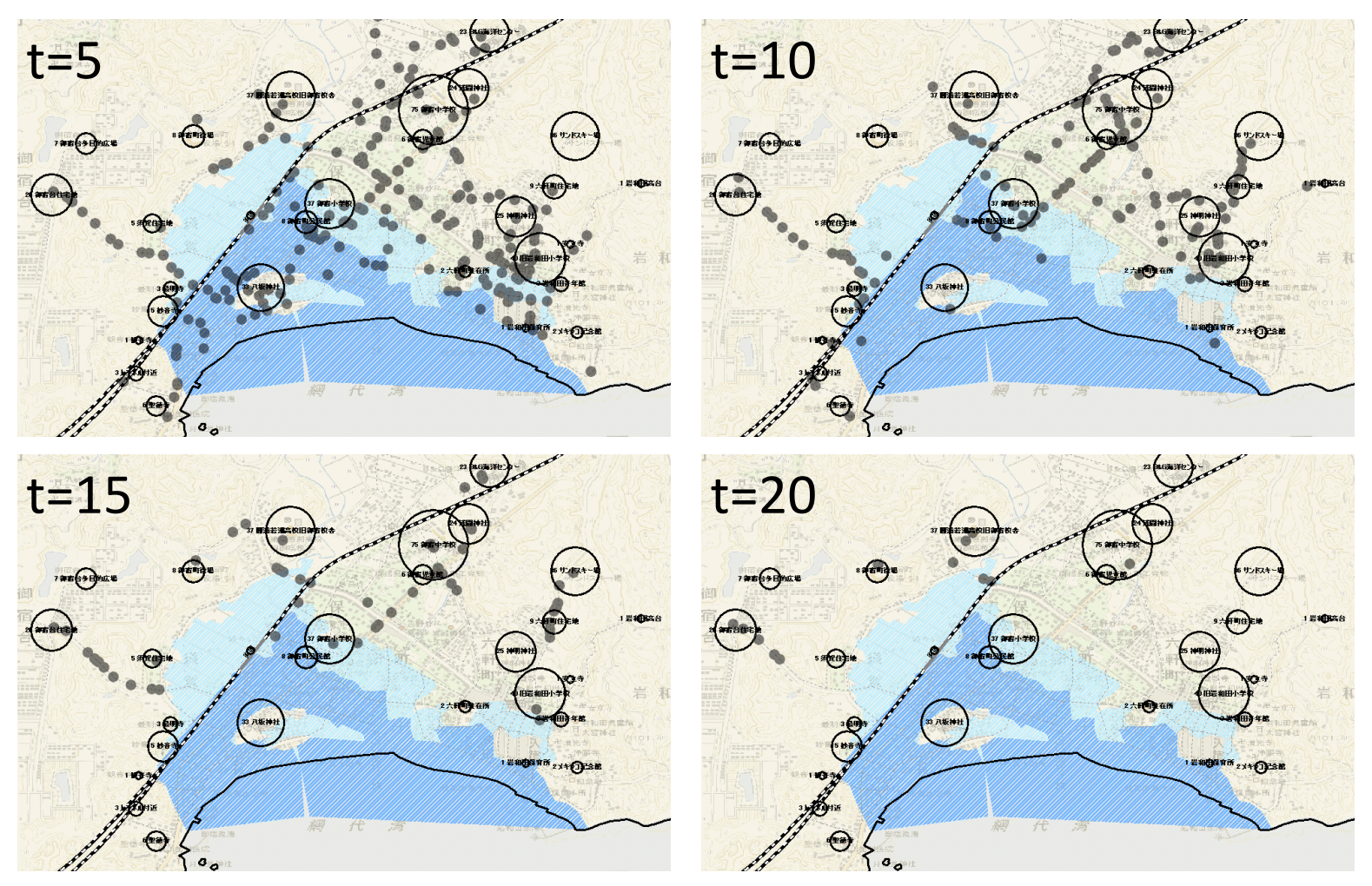

Fig. 3 Distribution of evacuees 5, 10, 15, and 20 minutes after an earthquake occurs (only 
questionnaire respondents are shown)

\subsubsection{Analysis using height above sea level}

Fig. 4 shows change in height above sea level during the envisioned evacuation behavior of each participant based on the survey. In places such as Onjuku where the geographical conditions are such that the road network and elevation differences are complicated, evacuees may in some cases evacuate to an area where the tsunami risk is high. However, among the evacuees (73 cases) involved in moving to a point $50 \mathrm{~m}$ or more above sea level, only $19 \%$ (14 cases) had a final destination with a height above sea level less than $50 \mathrm{~m}$. This and other results can be interpreted as demonstrating that most evacuees living on low ground aimed for high elevation when they evacuated. It is also the case, however, that not all of the evacuees sought high altitude.

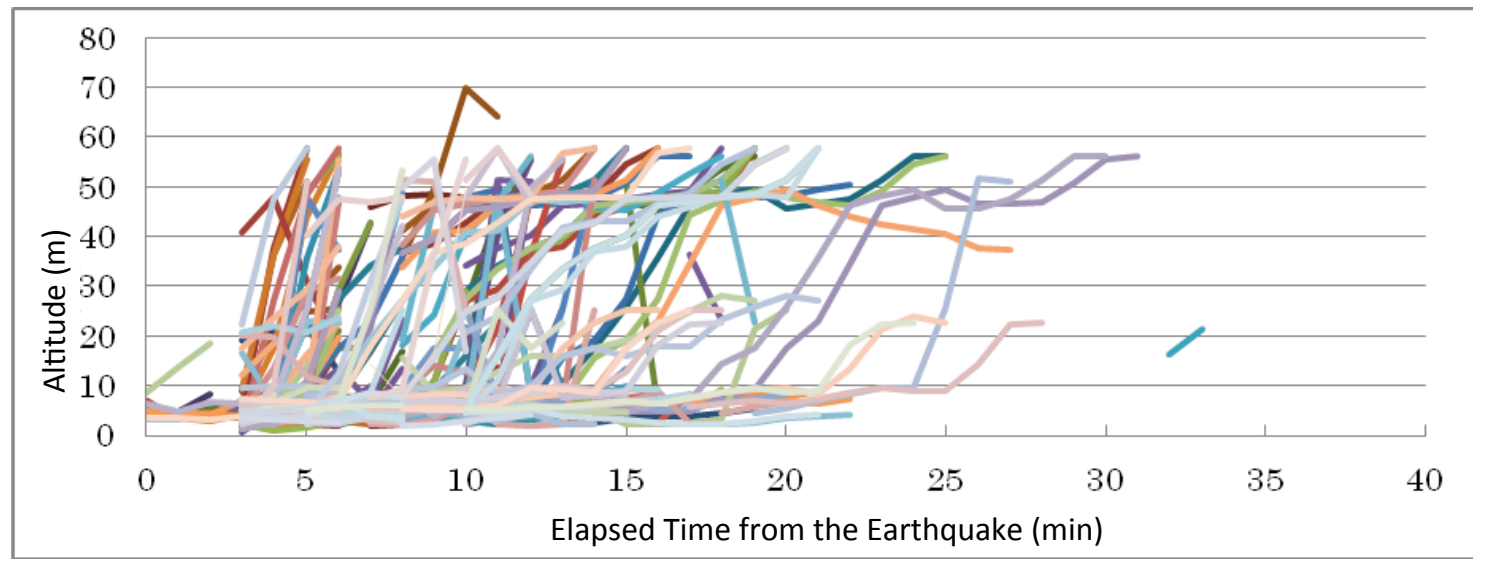

Fig. 4 Change in height above sea level during the envisioned evacuation behavior based on 2008 survey $(\mathrm{N}=255)$

\subsubsection{Analysis using distance from coastline}

In addition to height above sea level, distance from coastline is an important index that should be taken into account in tsunami evacuation. Fig. 5 shows graphically the distance from the coastline of each evacuee versus time. How far evacuees can get from the coast in the short period of time until the tsunami arrives has a stronger positive correlation than change in height above sea level.

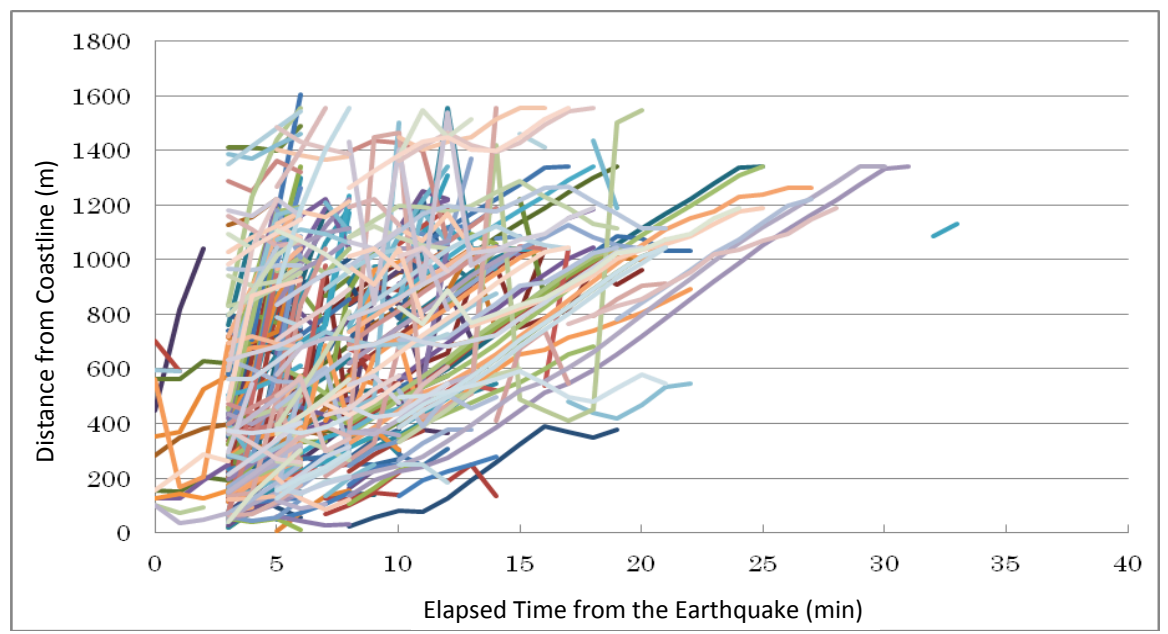

Fig. 5 Change in distance from coastline during envisioned evacuation behavior based on 2008 survey

$$
(\mathrm{N}=255)
$$




\subsubsection{Analysis using estimated flood zones}

Fig. 6 shows change in numbers of people performing evacuation behavior inside and outside the estimated flood zones of the Genroku and Empo earthquakes (excluding people who have already arrived at evacuation points). In this scenario, the tsunami arrives at the coast 15 minutes after it occurs. The figure shows that until approximately 10 minutes after the earthquake occurs, $30-50 \%$ of evacuees are performing evacuation behavior inside the estimated flood zones. However, within the 15 minutes predicted until the tsunami's arrival in the scenario, most evacuees have completed their evacuation behavior, and the majority of those still evacuating have managed to evacuate to outside of the flood area.

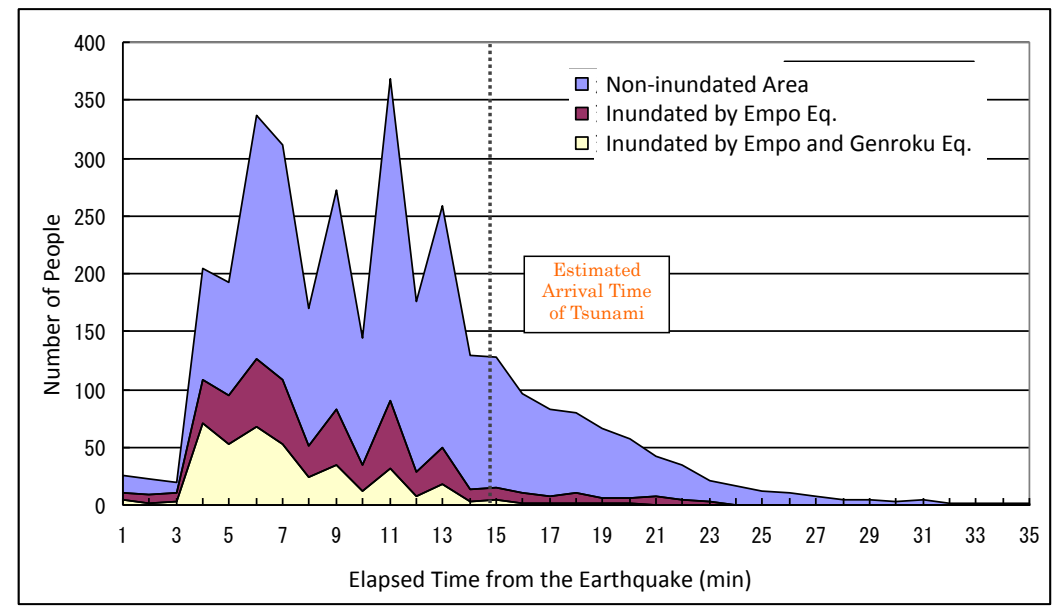

Fig. 6 Change in numbers of people performing evacuation behavior inside and outside the estimated flood zones (excluding people who have already arrived at evacuation points) based on 2008 survey

\section{SPATIAL ANALYSIS OF EVACUATION DURING TOHOKU EARTHQUAKE AND TSUNAMI BASED ON 2011 QUESTIONNAIR SURVEY}

\subsection{Spatial analysis of evacuation behavior of inhabitants}

When the Great East Japan Earthquake struck, tremors with a seismic intensity of 4 on the Japanese scale were observed in Onjuku. There was concern about tsunami damage, and a major tsunami warning was issued. Consequently, a tsunami height of $0.9 \mathrm{~m}$ was recorded, but there was no loss of life.

With regard to the earthquake measures in Onjuku, Table 2 shows the main response directly after the earthquake based on interviews.

An initial response that included calling for evacuation and opening an evacuation center was completed before the first wave of the tsunami arrived. The call to evacuate was implemented by broadcasting a major tsunami warning four times using the Disaster Prevention Wireless System, in conjunction with municipal fire fighting team patrols. Although places not originally designated as evacuation centers (Onjukudai Assembly Hall, Health Center, etc.) were opened after the arrival of the first wave, the fact that the evacuation order was not announced until after the arrival of the first wave suggests that the authorities were struggling with their response. One general problem highlighted by this disaster is the large number of reported cases of firemen becoming victims as a result of the volunteer fire department's deployment to the coast ${ }^{11)}$. Onjuku is no exception in assigning the municipal fire fighting team to patrol near the coast, and this issue requires discussion in future.

Table 2 Response directly after earthquake in Onjuku (drawn up based on interviews and documents provided by authorities in Onjuku) 


\begin{tabular}{|c|c|c|}
\hline Date & Time & Action \\
\hline \multirow[t]{10}{*}{$3 / 11 / 11$} & $14: 46$ & Earthquake occurs (seismic intensity 4) \\
\hline & $14: 54$ & $\begin{array}{l}\text { Disaster Prevention Wireless System (major tsunami warning issued, several } \\
\text { times hereafter) }\end{array}$ \\
\hline & 15:05 & Municipal fire fighting team patrols near coast calling for evacuation \\
\hline & $15: 10$ & Evacuation center opens (gymnasium of former Iwawada Elementary School) \\
\hline & $15: 15$ & Municipal fire fighting team ordered to evacuate temporarily to safe place \\
\hline & $15: 18$ & Disaster Response HQ established \\
\hline & $15: 20$ & 1st wave of tsunami arrives \\
\hline & $15: 31$ & $\begin{array}{l}\text { Disaster Prevention Wireless System (call for inhabitants near coast to } \\
\text { evacuate to high ground, several times hereafter) }\end{array}$ \\
\hline & $16: 20$ & $\begin{array}{l}\text { Evacuation centers open (B\&G Gymnasium, Onjukudai Assembly Hall, Health } \\
\text { Center) }\end{array}$ \\
\hline & $16: 45$ & $\begin{array}{l}\text { Disaster Prevention Wireless System (evacuation order/information about } \\
\text { evacuation sites, several times hereafter) }\end{array}$ \\
\hline \multirow[t]{2}{*}{$3 / 12 / 11$} & $13: 50$ & Major tsunami warning $\rightarrow$ changed to tsunami advisory \\
\hline & $14: 30$ & $\begin{array}{l}\text { Evacuation order lifted, evacuation centers closed, Disaster Response HQ } \\
\text { disbanded }\end{array}$ \\
\hline
\end{tabular}

\subsection{Overview and characteristics of 2011 questionnaire survey}

Here, points of difference from the 2008 questionnaire survey are considered. Table 3 lists basic information on the (assumed) tsunami in the 2008 and 2011 questionnaire surveys. The time of occurrence is roughly the same, with both tsunami occurring during the daytime, but the time from occurrence until arrival is different: 15 minutes in the 2008 survey, and 34 minutes in the 2011 survey. Also, the expected tsunami height in the 2008 survey is $8 \mathrm{~m}$, whereas the expected height of the tsunami resulting from the earthquake on March 11 is $2 \mathrm{~m}$ (the actual height of the tsunami when it arrived in Onjuku was $0.9 \mathrm{~m}$ ). There is scope for considering the extent of the effect of these differences when comparing the two surveys, but the important point is to compare the envisioned evacuation behavior of inhabitants in 2008 and their actual behavior in response to the real tsunami. Tsunami height has a large influence on resulting damage, but the authors consider that during the Great East Japan Earthquake disaster, there was enough information after the earthquake, including reports from other regions, for inhabitants to embark on evacuation. Therefore, tsunami height was judged to have little effect when comparing the evacuation behavior of inhabitants before the arrival of the tsunami.

Table 3 Comparison of basic information on (assumed) tsunami in 2008 and 2011 questionnaire surveys

\begin{tabular}{|c|c|c|}
\hline $\begin{array}{c}2008 \text { earthquake } \\
\text { (assumed) }\end{array}$ & $\begin{array}{c}\text { 2011 survey } \\
\text { (measured) }\end{array}$ \\
\hline $12: 00$ & Time of occurrence & $14: 46$ \\
\hline $\begin{array}{c}\text { Major tsunami } \\
\text { warning }\end{array}$ & Warning/advisory & $\begin{array}{c}\text { Major tsunami } \\
\text { warning }\end{array}$ \\
\hline $12: 15$ & $\begin{array}{c}\text { Tsunami arrival } \\
\text { time }\end{array}$ & $15: 20$ \\
\hline $8 \mathrm{~m}$ & Tsunami height & $2 \mathrm{~m}$ \\
\hline
\end{tabular}

Next, the characteristics of the 2011 questionnaire survey are described. The answers to "Questions regarding behavior directly after the earthquake struck" in the 2011 survey were not restricted to information about evacuation behavior. The survey inquired comprehensively about all movement behavior on March 11, 2011, and so the answers included daily behaviors such as shopping and meals, behavior involving returning home from or going to another location, and behaviors such as going to see the sea and patrolling the coast as part of the volunteer fire department. Therefore, it is possible to 
examine the results by way of observations/analyses based on actual circumstances that could not be seen in the analysis of envisioned routes based on the 2008 survey.

Also, the fact that circumstances such as evacuation sites were different must be taken into account in the analysis. In the 2008 survey, evacuation behavior was inputted without considering information on evacuation sites or evacuation restrictions, but in reality, four places were opened as evacuation sites (former Iwawada Elementary School, Onjukudai Assembly Hall, Health Center, and B\&G Gymnasium; see Fig. 7). Because there was not necessarily a need to evacuate to these sites, a wide variety of evacuation behavior was seen in reality, but this information about the opening of evacuation sites is considered to have had a substantial effect on the evacuation behavior of respondents.

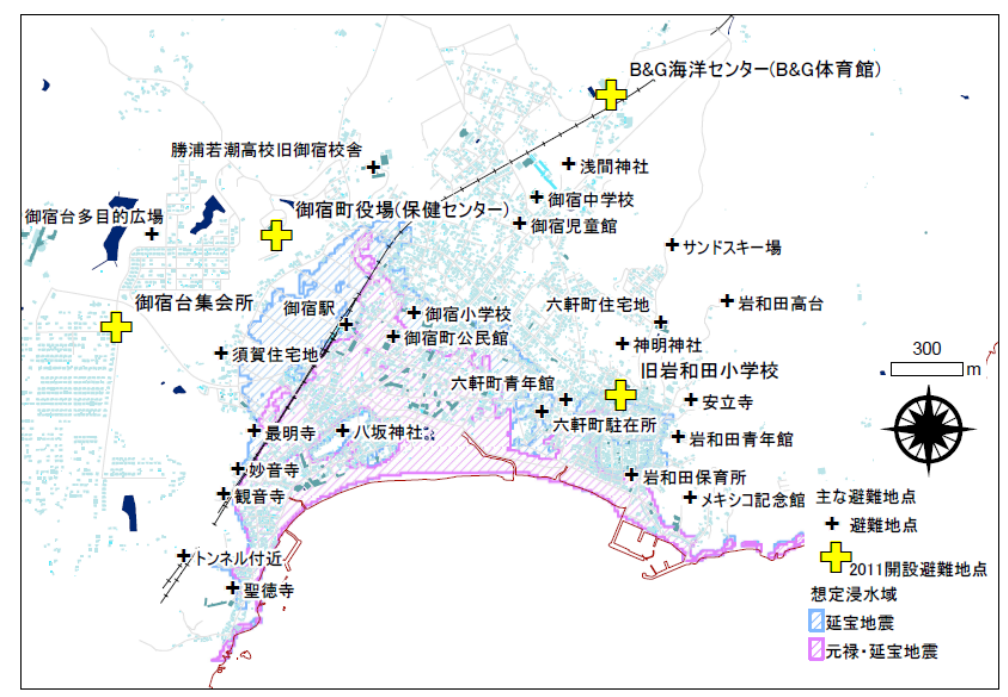

Fig. 7 Evacuation sites opened after the 2011 Great East Japan Earthquake

Given the above-mentioned points of difference, the data used in the spatial analysis of the 2011 questionnaire survey results are detailed here. The survey form comprised the following:

\subsubsection{Questions regarding behavior directly after the earthquake struck}

Circumstances at the time the earthquake struck (2:46 PM) (where they were and who they were with), subsequent movement behavior (movement site, movement route, arrival time, means of movement, and accompanying people).

\subsubsection{Questions regarding reasons for decisions made that day and awareness of tsunami protection}

Basis for movement behavior that day (recognition of flood risk, whether they recognized the warning, whether they recognized the call to evacuate, source of information on tsunami, stage at which they were aware that it was an emergency situation, stage at which they decided to evacuate, reason for choosing/changing evacuation site, basis of selection of evacuation route, and reason for not performing evacuation behavior), recognition of tsunami risk/interest in disaster prevention (knowledge of past tsunami, oral tradition in the area, degree of contact with hazard maps, recognition of flood risk after earthquake disaster, and earthquake preparation carried out after earthquake disaster).

\subsubsection{Individual attribute/Other}

Sex, age, occupation, number of members in household, number of years of residence, whether there are people in the household who may have difficulty evacuating, and whether they responded to 2008 questionnaire survey. 
Similar to the 2008 survey, the questionnaire survey was distributed along with a public relations magazine in August 2011. The number of forms distributed was 2,272, and 446 valid responses were obtained. According to the survey results, three of the four places opened as evacuation sites, former Iwawada Elementary School, Onjuku Town Hall (Health Center), and Onjukudai Assembly Hall, were used in 9, 15, and 41 cases, respectively, but the use of the B\&G Oceanic Center (B\&G Gymnasium) was relatively small, at 5 cases. With regard to movement route selection, more routes directed towards the Onjuku Town Hall (Health Center) were used compared to the 2008 survey. See the report by Isagawa et al. for further details of the survey results ${ }^{12}$.

As with the 2008 questionnaire survey, this research takes the "Questions regarding behavior directly after the earthquake struck" as the subject of analysis, and examines the replies from the perspective of height above sea level, distance from coastline, and number of people remaining in estimated flood zones.

\subsection{Spatial analysis of evacuation behavior of inhabitants}

\subsubsection{Basic information}

In the same way as the analysis based on the results of the 2008 survey, in this section, the spatial distribution of evacuation behavior of respondents for each time $t$ is derived, and an evaluation using the indices of height above sea level, distance from coastline, and estimated flood zones is conducted. By combining the distribution of respondents and each index, the indices can be standardized with the 2008 survey and the actual behavior of inhabitants evaluated.

\subsubsection{Analysis using height above sea level}

Fig. 8 depicts graphically the change in height above sea level of all respondents until 240 minutes after the earthquake occurs. Places where height above sea level changes over a time interval indicate movement behavior.

Fig. 9 shows the number of people moving versus elapsed time. It demonstrates that there are periods when movement behavior intensifies and periods when it settles down. Taking the time when the number of people moving is zero or one person as the main criterion, actual behavior after the earthquake is broadly divided into four phases and their characteristics are considered.

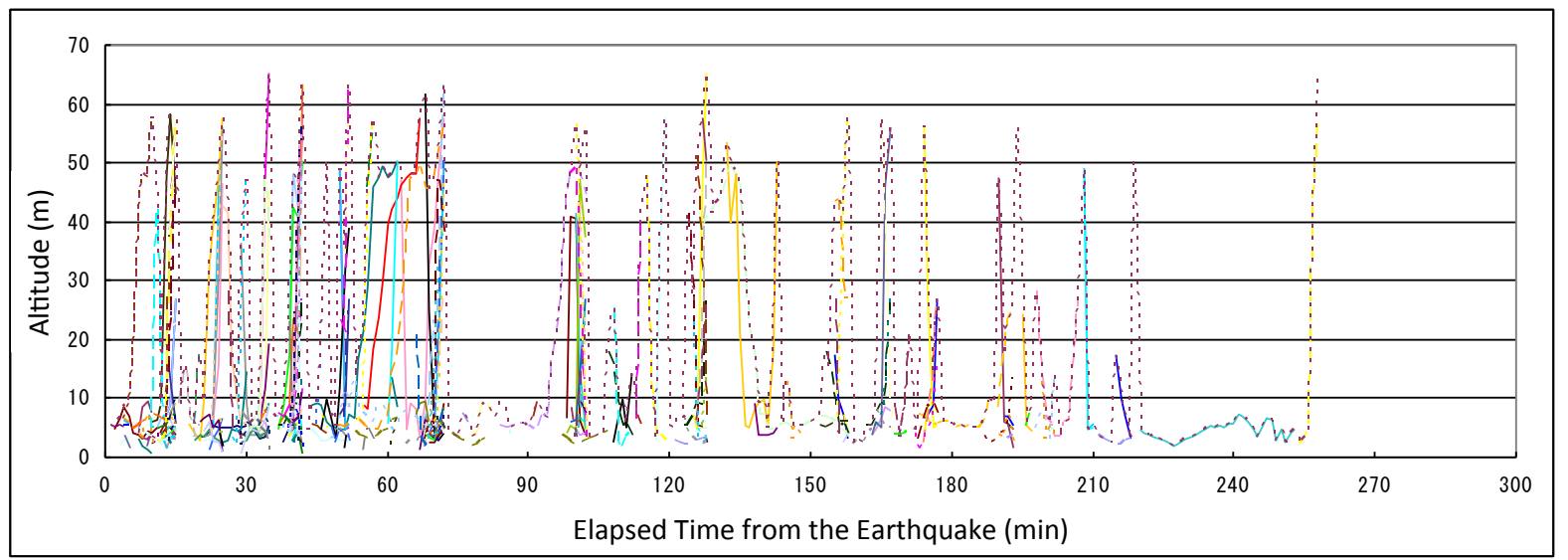

Fig. 8 Change in height above sea level during actual evacuation behavior based on 2011 survey $(\mathrm{N}=$ 140) 


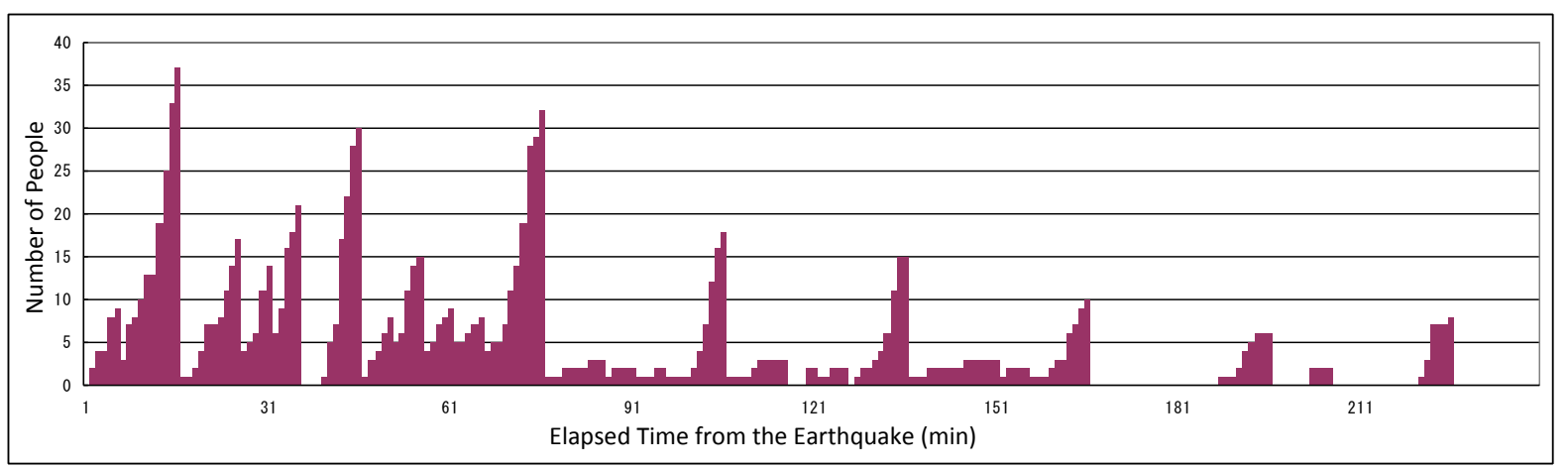

Fig. 9 Change in actual number of people evacuating based on 2011 survey $(\mathrm{N}=140)$

Phase 1: Initial response period (0-17 minutes after disaster strikes). The period from directly after the disaster strikes until approximately 17 minutes later is taken as Phase 1. During the initial period, many inhabitants immediately commence evacuation behavior, but many inhabitants also take actions in concern for the safety of their homes or their families/relatives.

Phase 2: Period of intensification of evacuation behavior (17-40 minutes after disaster strikes). In Phase 2, inhabitants who were waiting to see what would happen start to evacuate as a result of broadcasts via the Disaster Prevention Wireless System urging evacuation and patrols by members of the fire fighting team. However, behavior involving returning home from a distant location, such as a place of work, can also be observed.

Phase 3: Peak evacuation behavior period (40-80 minutes after disaster strikes). Evacuation behavior is most intense during this period. The first wave of the tsunami arrives 35 minutes after the disaster strikes, and this is also when information starts to circulate via, for example, television. During this period, there is considered to be a large amount of so-called "secondary evacuation behavior" when surrounding anxiety impels inhabitants to evacuate.

Phase 4: Period of contraction of evacuation behavior ( 80 minutes after disaster strikes). From Phase 4 onwards, evacuation behavior contracts. From 100 minutes after the disaster strikes, a large amount of movement from high to low ground can also be seen. This behavior can be assumed to include returning to, for example, one's home.

\subsubsection{Analysis using distance from coastline}

Fig. 10 shows change in distance from the coast. The graph shows that there is a large amount of behavior, corresponding to mostly positive slopes, but the trend is not as obvious as that in the 2008 survey. This shows the diversity of behavior in situations where a tsunami risk is recognized in reality. For example, altruistic behavior due to concern for children or relatives, work behavior that derives its behavioral intention from the company/organization that the individual belongs to, returning-home behavior, daily behavior, etc. As shown in Fig. 11, 23.4\% of respondents exhibited movement behavior that was not evacuation related. 


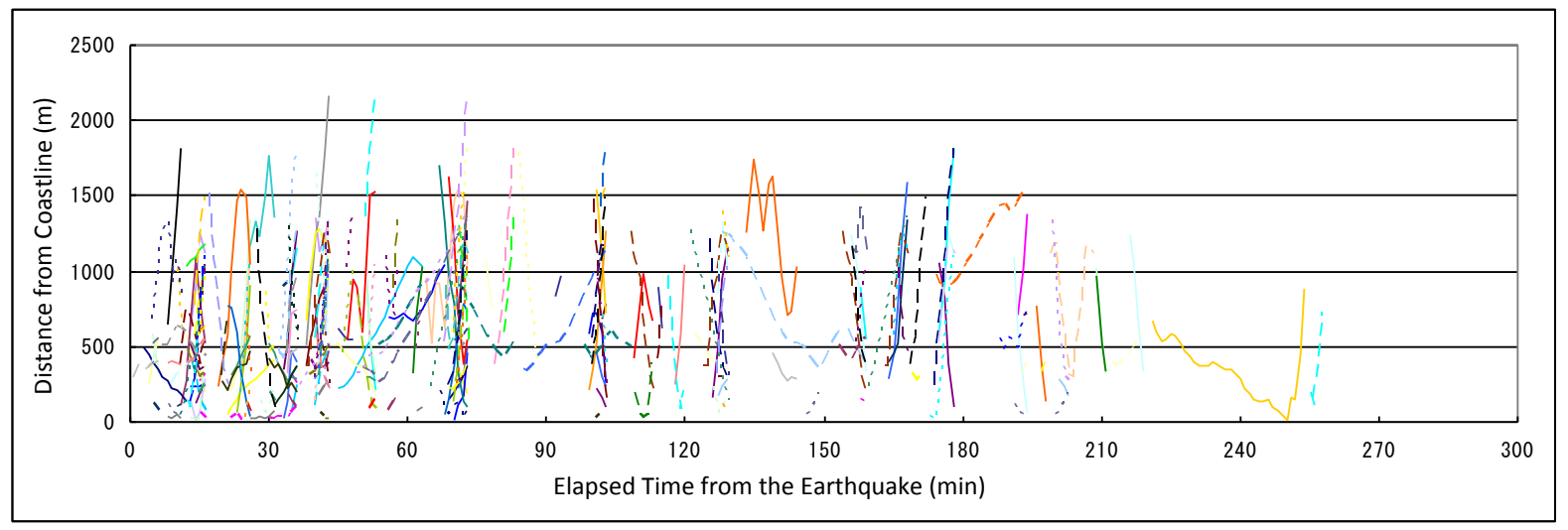

Fig. 10 Change in distance from coastline during actual evacuation behavior based on 2011 survey (N $=140)$

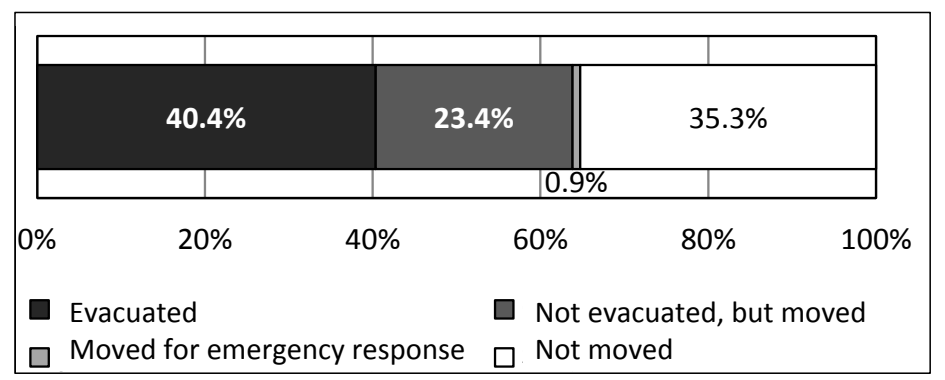

Fig. 11 Summary of behavior of respondents based on 2011 survey $(N=431$, free answer method)

\subsubsection{Analysis using estimated flood zones}

Fig. 12 shows numbers of people moving inside and outside the flood zones between earthquake occurrence and 120 minutes later. It is evident that the proportion of inhabitants performing movement behavior inside the flood zones is much greater than in the 2008 survey. Also, after the arrival of the tsunami, the proportion of movement behavior inside the flood zones increases further. This behavior becomes increasingly dangerous after the second and third waves of the tsunami, and measures must be put in place against such behavior.

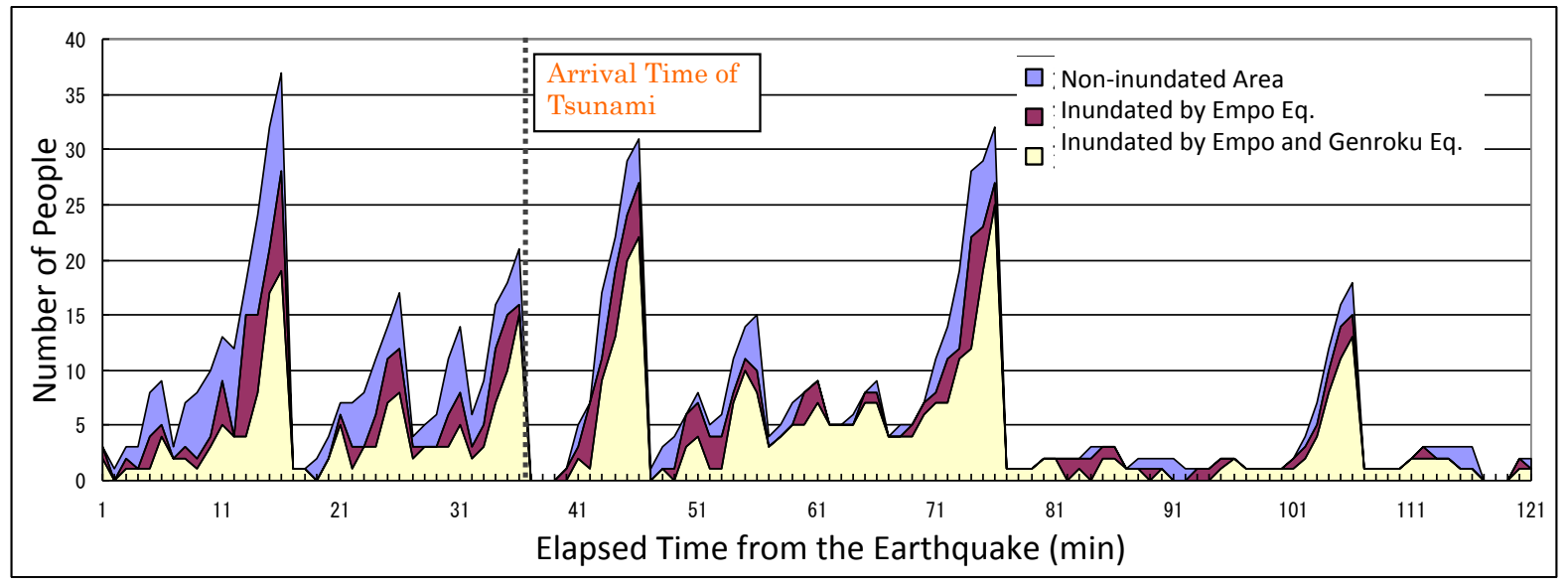

Fig. 12 Change in numbers of people performing evacuation behavior inside and outside estimated flood zones (excluding people who have already arrived at evacuation points) based on 2011 survey 


\section{COMPARISON OF ENVISIONED AND ACTUAL EVACUATION BEHAVIOR}

\subsection{Spatial analysis of evacuation behavior of inhabitants}

In this section, the evacuation behavior obtained from the 2008 survey is referred to as envisioned evacuation behavior and the evacuation behavior obtained from the 2011 survey as is referred to as actual evacuation behavior. The characteristics of these two behaviors are compared here. As mentioned earlier, the conditions of the assumed earthquake in the 2008 survey and those of the 2011 Great East Japan Earthquake differ greatly. Therefore, the comparison is done after bringing together the population properties by extracting (1) movement behavior considered to be evacuation, and (2) behavior until several minutes after the arrival of the first tsunami wave (0-45 minutes after earthquake occurs), from the summarized results of the 2011 survey. Similar to the analyses performed up to now, the indices for the comparison are taken to be (1) height above sea level, (2) distance from coastline, and (3) number of people remaining in estimated flood zones.

\subsection{Comparison of evacuation behavior from perspective of height above sea level}

Figures 13 and 14 show change in height above sea level during evacuation behavior performed from the time of the assumed earthquake in the 2008 survey and from the time of the 2011 earthquake until several minutes after the arrival of the first tsunami wave. Looking at the actual evacuation behavior, there is a large amount of movement behavior that originates during the 10 minutes after the warning is issued and calls to evacuate begin, and this can be interpreted as showing that these methods serve as impetuses for evacuation. On the other hand, compared to the envisioned evacuation behavior, a relatively large number of evacuees who started their evacuation behavior after the arrival of the first tsunami wave (indicated by lines with starting points after the arrival of the first wave) are found in the case of the actual evacuation behavior. This trend is considered to be related to the timing of evacuation decision-making (Fig. 15, right). Also, most of the actual evacuation behavior appears as lines with steep gradients. This is considered to be because cars were frequently used as the means of movement in actual evacuation behavior (Fig. 15, left), and this demonstrates a very different trend from the envisioned evacuation behavior.

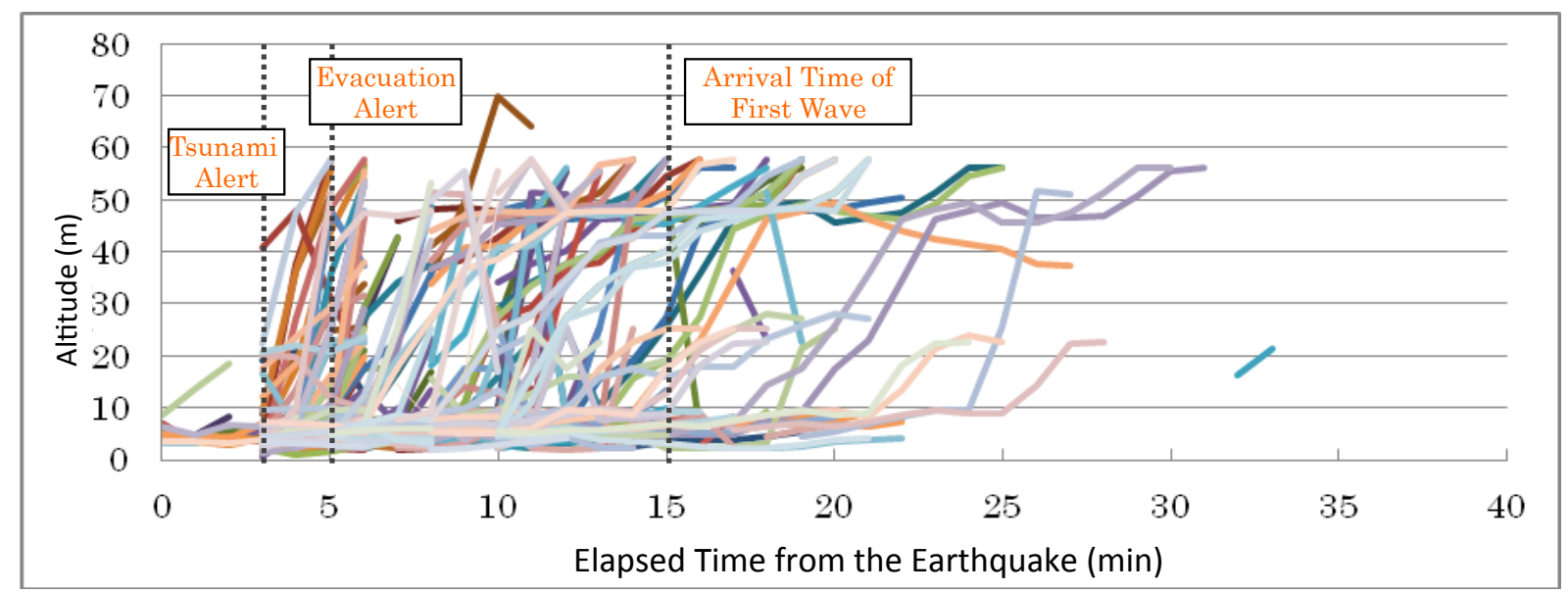

Fig. 13 Change in height above sea level during envisioned evacuation behavior $(\mathrm{N}=255)$ 


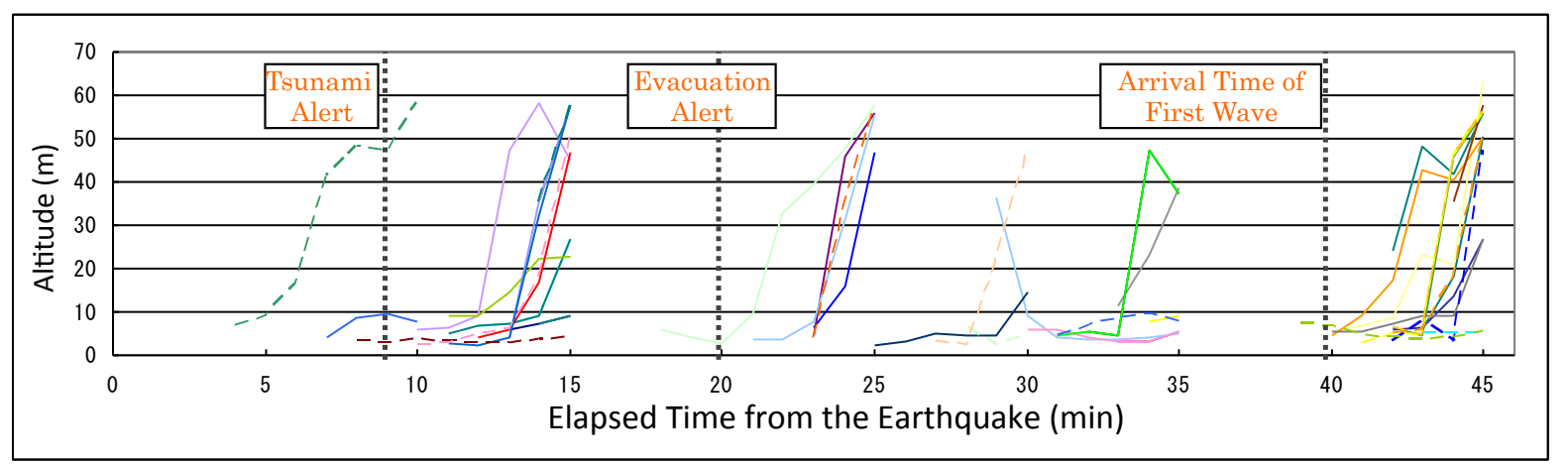

Fig. 14 Change in height above sea level during actual evacuation behavior $(0-45$ minutes after earthquake strikes, $\mathrm{N}=94$ )
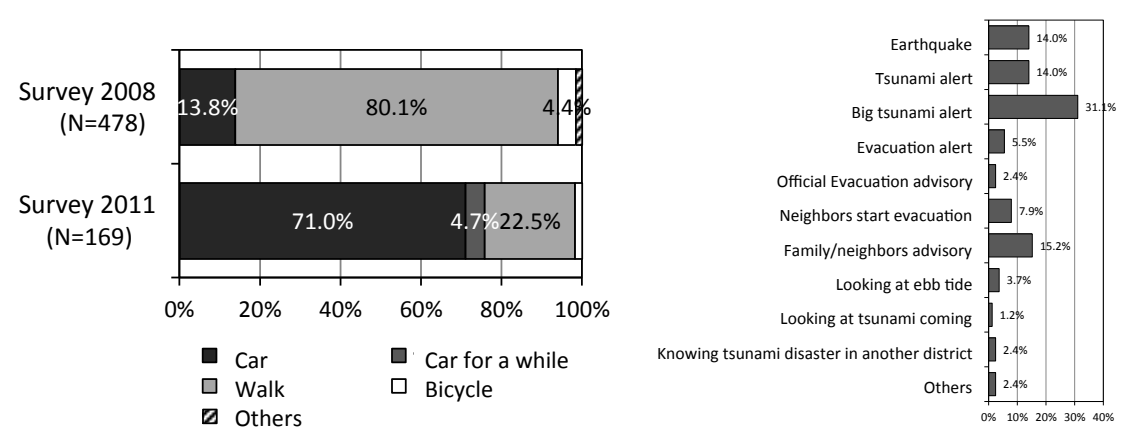

Fig. 15 Means of movement used in evacuation (left) and timing of evacuation decision-making (right,

$$
\mathrm{N}=164 \text { ) }
$$

\subsection{Comparison of evacuation behavior from perspective of distance from coastline}

Figures 16 and 17 show change in distance from coastline during each evacuation behavior. Cases of evacuees getting $2 \mathrm{~km}$ or more distant from the coastline are found among the actual evacuation behavior, and this is a trend that was not observed in the envisioned evacuation behavior. This could be considered to be a result of the earlier-mentioned point of cars being frequently used as the means of migration and the fact that evacuation behavior in which the houses of relatives/acquaintances were chosen as destinations ${ }^{12)}$ was found in the actual evacuation behavior.

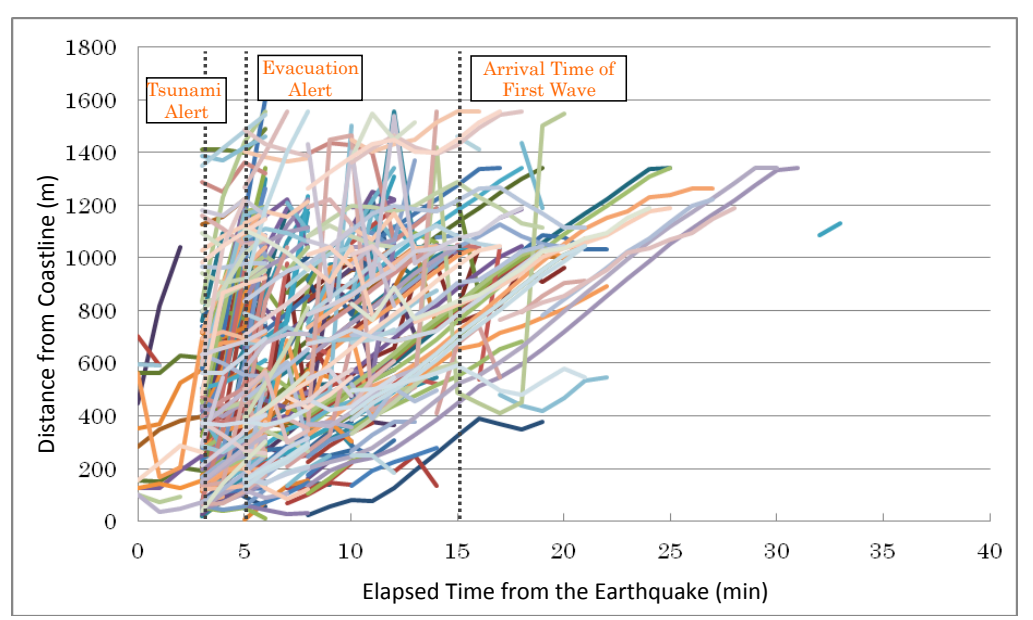


Fig. 16 Change in distance from coastline during envisioned evacuation behavior $(\mathrm{N}=255)$

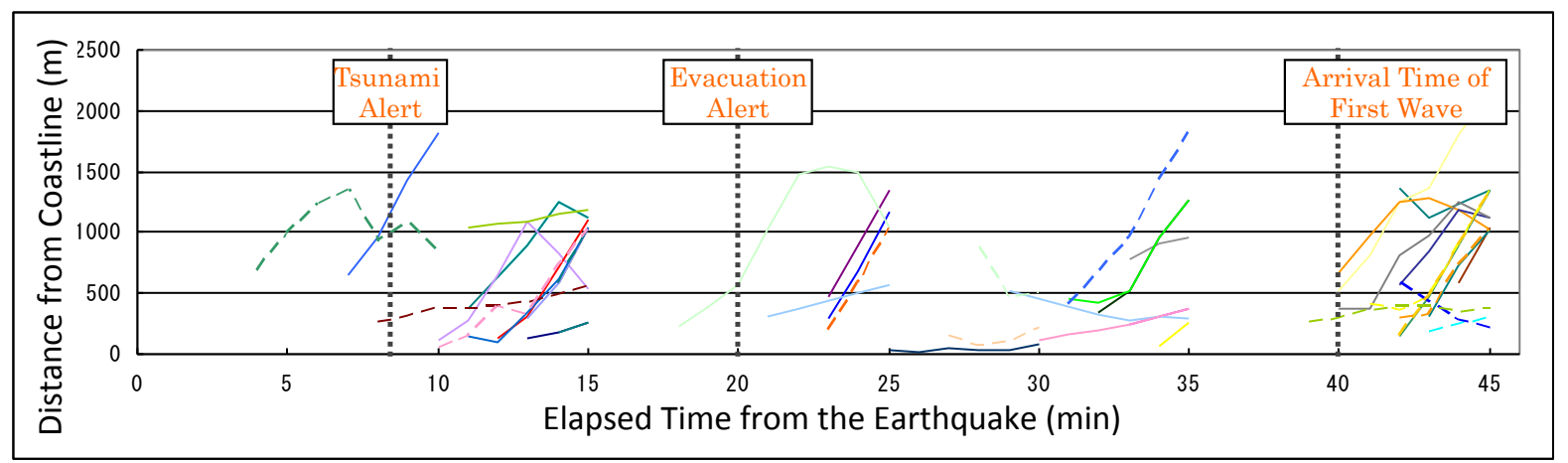

Fig. 17 Change in distance from coastline during actual evacuation behavior (0-45 minutes after earthquake strikes, $\mathrm{N}=94$ )

\subsection{Comparison of numbers of people inside estimated flood zones}

Figures 18 and 19 show change in numbers of people inside the flood zones As mentioned earlier, the amount of movement behavior inside the flood zones was conspicuous with regard to overall behavior during the Great East Japan Earthquake disaster, but if we look at evacuation behavior only, it is evident that the difference in proportion from the envisioned evacuation behavior is much less.

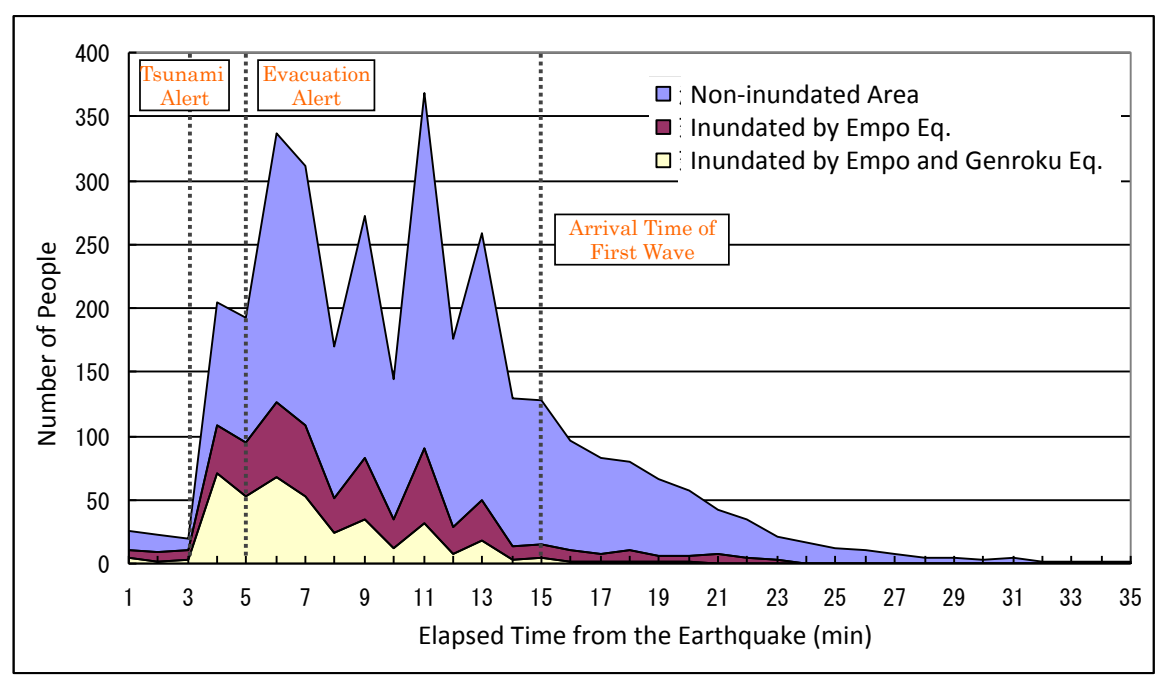

Fig. 18 Change in numbers of people inside flood zones during envisioned evacuation behavior 


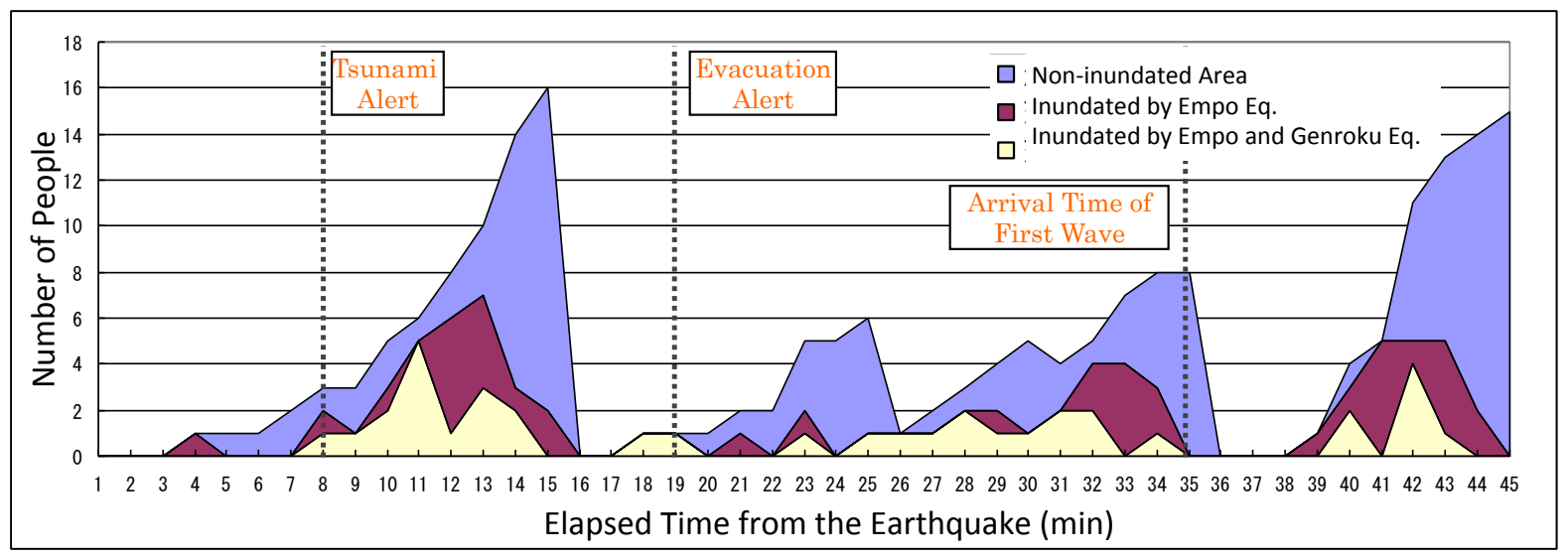

Fig. 19 Change in numbers of people inside flood zones during actual evacuation behavior

\section{CONCLUSIONS}

This study was a comparative analysis of envisioned and actual evacuation behaviors using three indices based on questionnaire surveys carried out in 2008 and 2011. The conclusions drawn from the results are summarized as follows:

(1) The general approach of local governments to evacuation in tsunami protection focuses only on avoiding the crisis caused by the first tsunami wave. However, because in reality there are several phases of evacuation behavior, including secondary evacuation, it is advisable that measures such as the opening of evacuation centers are reviewed for each phase and actions such as adding to the open evacuation centers are considered as needed.

(2) Even if evacuation by car is not often observed in the envisioned behavior, it is possible that the majority of cases will involve evacuation by car, as was the case in Onjuku. During the Great East Japan Earthquake disaster, negative effects due to evacuation by car were discovered in some cases, and so traffic policy must be included in examinations of evacuation.

(3) Evacuation over long distances was occasionally seen in association with car use. Depending on the circumstances, it may be preferable to have cooperation between neighboring towns and villages involving, for example, sharing information and receiving evacuees.

(4) The results for number of people inside the flood zones over time show that, in many cases, inhabitants who do not implement evacuation behavior remain in the flood zone. Consideration must be given to how to urge these people to evacuate.

\section{ACKNOWLEDGMENT}

Part of the work in this study was carried out during the period of a Grant-in-Aid for Scientific Research on Innovative Areas (B), Inspection of Urban Reconstruction Plans after the Indian Ocean Tsunami and Evaluation of Tsunami Risk of Asian Towns due to Global Warming (No. 23404019), and a University of Tsukuba project, Integrated Risk Management of Complex Disaster caused by Major Earthquake. We would like to thank the residents of Onjuku who cooperated with our questionnaire surveys in 2008 and 2011.

\section{REFERENCES}

1) Mainichi Japan, Morning Edition, October 12, 2011 (in Japanese). 
2) Central Disaster Management Council: Outline of the Report of the Committee for Technical Investigation on Countermeasures for Earthquakes and Tsunami Based on the Lessons Learned from the "2011 off the Pacific coast of Tohoku Earthquake," 2011.

3) Fujioka, M., Ishibashi, K., Kaji, H., and Tsukagoshi, I.: Multi Agent Simulation Model for Evaluating Evacuation Management System against Tsunami Disaster, Journal of Architecture and Building Science, No.562, 2002, pp.231-236 (in Japanese).

4) Katada, T., Kuwasawa N., Kanai, M., and Hosoi, K.,: Disaster Education for Owase Citizen by Using Tsunami Senario Simulator and Evaluation of That Method, Sociotechnica, Vol.2, 2004, pp.199-208 (in Japanese).

5) Watanabe, K., and Kondo, A.,: Development of Tsunami Evacuation Simulation Model to Support Community Planning for Tsunami Disaster Mitigation, Journal of Architecture and Building Science, No.637, 2009, pp.627-634 (in Japanese).

6) Isagawa, T., and Murao, O.,: Residents' Consciousness and Intention of Tsunami Evacuation Based on Spatial Data Analysis A Case Study of Onjuku Town, Chiba, Journal of Architecture and Building Science, No.648, 2010, pp.395-402 (in Japanese).

7) Takeuchi, H., Fuji, R., Mimura, N., Imamura, F., Satake, K., Tsuji, Y., Hochi, K., and Matsuura, T.,: Survey of run-up height of Empo Boso-oki Earthquake Tsunami on the coast from Chiba Prefecture to Fukushima Prefecture, Historical Earthquakes, No.22, 2007, pp.53-59 (in Japanese).

8) Tsuji, Y.,: Detailed Distribution of Human and House Damage of the 1703 Genroku Kanto Earthquake and its Accompanied Tsunami in Chiba Prefecture, Historical Earthquakes, No.19, 2004, pp.8-16 (in Japanese).

9) Geospatial Information Authority of Japan: Basic Map Information, http://www.gsi.go.jp/kiban, 2011.

10) Ishida, H., Taniguchi, M., Suzuki, T., and Furuya, H.,: Transportation Policy Evaluation based on the Relations between Domains and Dominated Territories of Each Transport Mode, Transport Policy Studies, Vol. 2, No.1, 1999, pp.14-25 (in Japanese).

11) Fire and Disaster Management Agency: Report on the 2011 off the Pacific coast of Tohoku Earthquake, 2011, http://www.fdma.go.jp/disaster/syobodan_katudo_kento/01/shiryo_06.pdf, 2011.

12) Isagawa, T., Murao, O., and Ohno, R.,: Coastal Residents' Behavior toward Tsunami: A Case Study of Onjuku Town, Chiba Prefecture, Proceedings of Learning from the 2011 Great East Japan Earthquake, 2013, pp.515-518 (in Japanese).

(Original Japanese Paper Published: September, 2012) (English Version Submitted: September 30, 2014) (English Version Accepted: November 23, 2014) 